\title{
Capital social y representaciones sociales sobre la prueba Papanicolaou
}

Social capital and social representations about the Papanicolaou test

\author{
Erika Patricia Rojas González ${ }^{1}$, Nemesio Castillo Viveros², y Rogelio \\ Rodríguez Hernández ${ }^{3}$
}

\begin{abstract}
Resumen
El presente trabajo aborda principalmente la literatura de los teóricos sociales Sergio Moscovici, seguido por el pensamiento de Denise Jodelet, Jean Claude Abric, José Antonio Castorina y Thomas Luckmann, entre otros, para ilustrar cómo la representación social constituye modalidades de pensamiento práctico orientados hacia la comprensión y dominio del entorno social, para después referir los elementos de ésta.

A lo largo del artículo se sustenta el supuesto que se formuló: "Los estereotipos, opiniones, creencias o valores que tienen las mujeres acerca del cáncer cervicouterino que habitan las zonas del centroponiente y norponiente, afectan la práctica de la prueba Papanicolaou" la cual sirvió de guía la investigación para presentar los elementos involucrados y comprobar el razonamiento del que se partió.
\end{abstract}

Palabras clave : Capital social, Representaciones sociales, Prueba Papanicolaou y mujeres.

\begin{abstract}
This research presents mostly the literature of social theorists' Sergio Moscovici, followed by the thinking of Denise Jodelet, Jean Claude Abric, José Antonio Castorina and Thomas Luckmann, among others, to illustrate

\footnotetext{
1 Sociologa, maestria en Ciencias Sociales y candidata a Doctora en Investigación por el Colech. cvnemesio@gmail.com

2 Miembro del Sistema Nacional de Investigadores Nivel I. Doctor en ciencias sociales por la Universidad Autónoma de Ciudad Juárez (2006-2008). Maestro en ciencias sociales para el diseño de políticas públicas por la Universidad Autónoma de Ciudad Juárez (2003-2005). Licenciado en Sociología por la Universidad Veracruzana (1998-2002). Excoordinador de la Licenciatura en Trabajo Social de la UACJ (2013-2015). Actualmente es profesor-investigador de tiempo completo en la Universidad Autónoma de Ciudad Juárez y Coordinador del Programa de Maestria Trabajo Social. http://orcid.org/0000-0001-9254-0183. cvnemesio@gmail.com.

3 Psicólogo, maesntro en Psicología y doctorado en Trabajo Social. cvnemesio@gmail.com
} 
how social representation constitutes modalities of practical thinking aimed at understanding and mastering of the social environment, so its elements can be referred.

Throughout this study the assumption that was formulated is sustained: "The stereotypes, opinions, beliefs or values that women, who live in the center west and north west areas of the Juarez city (target population) have about cervical cancer, affect to do the pap smear test" in which is based this research to present the involved elements and demonstrate the argument from which it started.

\section{Salud reproductiva}

La salud reproductiva es definida según la Organización Mundial de la salud (OMS), como el estado general de bienestar físico, mental y social en todos los aspectos relacionados con el sistema reproductor tanto de la mujer como del hombre, sobre sus funciones y sus procesos, es decir, es la capacidad de los individuos y de las parejas de disfrutar una vida sexual y reproductiva plena, saludable y sin peligros con la absoluta libertad para decidir de una manera responsable e informada (Universidad Nacional Autónoma de México, UNAM, 2014).

La salud reproductiva está encaminada al desarrollo de la vida, de las relaciones personales y no solamente al asesoramiento y la atención en materia de la reproducción y de las enfermedades de transmisión sexual. En cuanto al concepto de salud reproductiva, Heise (1995) asevera que ha evolucionado en muchos sentidos, ya no se refiere solamente a la planificación de la familia, como se entendía antes, específicamente en los años sesenta, sino que tiene un campo de acción mucho más amplio que sobrepasa el ámbito de lo biológico y se relaciona con los valores, la cultura y la realización personal de cada ser humano.

Es importante recalcar que la salud reproductiva, dentro del contexto social es parte integral del desarrollo sostenible de un país y se fundamenta en los derechos y deberes humanos individuales y sociales. Este concepto contempla, aparte de la planificación de la familia como era entendido en pasadas décadas, la educación sexual, la maternidad sin riesgo, el control de las enfermedades de transmisión sexual, la atención a las complicaciones del aborto en condiciones de riesgo, la incorporación de la 


\section{DOXA}

pISSN: 2395-8758

eISSN: en trámite

perspectiva de género y la atención de todas las necesidades relacionadas con la reproducción de la especie humana y el ejercicio de su potencial (Heise 1995).

Dentro de la salud reproductiva, es de suma importancia abordar los aspectos relacionados con la atención integral de la mujer y, una de las afecciones que la aquejan es el desarrollo del cáncer cervicouterino, el cual ha cobrado vidas tanto a nivel mundial, como en América Latina y no es la excepción en México, por lo que es importante mencionar:

En los países en desarrollo en cuestión de muertes por cáncer cervicouterino $(\mathrm{CaCu})$, las cifras de mortalidad por este padecimiento son muy altas, en cambio, en los países desarrollados en número de muertes por cáncer cervicouterino $(\mathrm{CaCu})$ ha disminuido considerablemente: en América del Norte con 14,670 casos, mientras que en Europa con 59,931 y en Australia con 14,370 casos por año. En América Latina, se estima que existen 68,818 casos por año. La incidencia en la región es de 21.2 casos por 100,000 mujeres, alcanzando valores superiores a 30 en países como México, Perú, Paraguay, Guyana, Bolivia, Honduras, Venezuela, Nicaragua (Centro Nacional de Equidad de Género y Salud Reproductiva, CNEGSR, 2017). En África subsahariana los casos anuales son de 78,000 seguido de India y el sudeste asiático con un total aproximadamente de 260,000 casos por año (Chirenje, 2017).

\section{Experiencias en países en desarrollo (México y América Latina)}

El Cáncer cervicouterino $(\mathrm{CaCu})$ es un problema de salud pública; es la segunda enfermedad neoplásica más frecuente y mortal en la población femenina en México (Castro et al: 2012). Según la Agencia Internacional de Investigación sobre Cáncer (IARC), señala que la infección por el Virus del Papiloma Humano por sus siglas (VPH) es el principal mecanismo implicado para el progreso de esta enfermedad; aproximadamente transcurren de 10 a 15 años entre la infección por VPH y el desarrollo del cáncer cervicouterino.

El Centro Nacional de Equidad de Género y Salud Reproductiva, señala que en México desde el año de 2006 el cáncer cervicouterino es la segunda causa de muerte por cáncer en las mujeres. "Cada año se estiman 13,960 casos con una incidencia de 23.3 casos por 100,000 mujeres. En el año 2013, se registraron 3,784 muertes en mujeres con una tasa de 7.0 
pISSN: 2395-8758

eISSN: en trámite

defunciones por 100,000 mujeres" (CNEGSR, 2016:1)

La experiencia de los países desarrollados en el control de las muertes por $\mathrm{CaCu}$ ha mostrado que el tamizaje basado en el Papanicolaou (Pap) es efectivo para reducir las tasas de incidencia y mortalidad, sobre todo si se realiza en el marco de un programa de prevención organizado (OPS, 2012). "En América Latina la mayoría de los programas de prevención del cáncer cervicouterino no ha logrado cumplir con sus objetivos debido principalmente a la baja cobertura del tamizaje, seguimiento y tratamiento de mujeres con lesiones precancerosas; esto se refleja en el alto índice de muertes en países que comprenden esta región" (Lazcano-Ponce et al, 2006: 3)

Según la NOM-014-SSA2-1994, en los países de primer mundo con programas de detección convenientes a través del estudio citológico cervical o prueba Papanicolaou, se ha observado una importante disminución de la mortalidad por cáncer cervicouterino, "atribuible a la detección de lesiones precursoras y preinvasoras", por lo que se deduce que un diagnóstico preventivo a tiempo ofrece la posibilidad de un tratamiento exitoso a bajo costo social.

En América latina el $\mathrm{CaCu}$ es el $10.4 \%$ de la incidencia de cáncer, por debajo también del cáncer de mama $(26.6 \%)$ y es el $11.8 \%$ de la mortalidad por cáncer, estas cifras según la Organización Panamericana de la Salud se han mantenido desde el año 2002 (OPS, 2016). El Sistema Nacional de Salud Mexicano brinda atención médica aproximadamente a 9,000 casos de $\mathrm{CaCu}$ invasor y se registran 4,000 muertes anualmente (Castro et al: 2012).

A diferencia de otros tipos de neoplasias ${ }^{4}$, una muerte por cáncer cervicouterino es una muerte prevenible, ya que si éste es detectado a tiempo puede tratarse y disminuir o eliminar el riesgo de muerte. Es importante subrayar que este tipo de cáncer es cien por ciento curable si se diagnostica a tiempo por medio de una prueba, ya que esta enfermedad es precedida durante meses o años de una lesión premaligna in situ; un diagnóstico temprano y oportuno permitiría una vida totalmente normal (Lamont, 1994).

4. Displasia: Formación anormal en alguna parte del cuerpo de un tejido nuevo de carácter tumoral, benigno o maligno (OMS, 2016). 
Como ya lo he señalado, a pesar de que existe un método de diagnóstico, llamado prueba Papanicolaou o Pap, que permite detectar a tiempo el cáncer cervicouterino $\mathrm{y}$, que es relativamente sencilla, inocua y accesible para la población femenina (Walboomers,1999, citado en Berumen, 2006), las altas tasas de mortalidad por esta causa en México, señalan que los programas de prevención y detección oportuna no están cumpliendo a cabalidad el objetivo para el cual fueron creados.

Avanzando en este razonamiento, Hidalgo-Martínez (2006) señala tres factores que intervienen para una disminución exitosa de la mortalidad por $\mathrm{CaCu}$ en México: 1) acceso regular a los servicios de salud, 2) contar con personal capacitado para la realización del tamizaje cervical, 3) dar seguimiento oportuno y adecuado a los resultados anormales resultantes.

Diferentes estudios cuantitativos (Lazcano-Ponce et al. 2006; Castro, 2012; Martínez y Rodríguez, 2010) han abordado los factores sociodemográficos que permiten ubicar a la población más vulnerable para el no uso del examen, así también otras investigaciones cualitativas (Hidalgo-Martínez, 2006); Valenzuela y Miranda, 2001; Caraveo, 2004) han señalado la importancia de los factores culturales en el no uso del examen, sin embargo, la presencia de altas tasas de mortalidad por $\mathrm{CaCu}$ señalan la necesidad de seguir ahondando en los factores culturales que impiden el uso a la población vulnerable.

$\mathrm{Si}$ bien la vacuna contra el virus del papiloma se aplica aproximadamente desde el año 2006 en México, según la modificación de la NOM-014-SSA2-1994 se administra la vacuna a niñas de quinto grado o bien, de 11 años no escolarizadas en dos dosis, ésta proporciona protección contra los virus 16 y 18 que según la SS (2017) causan aproximadamente el $70 \%$ de los casos donde se desarrolla cáncer cervicouterino en las mujeres en este país.

Además de proporcionar protección contra los tipos de VPH mencionados y otros incluidos en estas vacunas, se ha descubierto que las vacunas proveen una protección parcial contra otros pocos tipos de VPH (6 y 11) que son asociadas con lesiones precancerosas, como las verrugas genitales y displasia vaginal de bajo grado y, que todavía están en investigación por lo que se llama protección cruzada. Las vacunas no protegen contra otras enfermedades de transmisión sexual, ni tratan infecciones por VPH existentes o enfermedades ya existentes causadas por el 
pISSN: 2395-8758

eISSN: en trámite

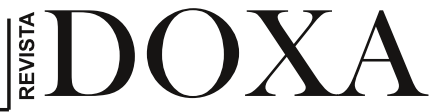

virus del VPH (NIH, 2018).

Dado que las vacunas disponibles en la actualidad no protegen contra todas las infecciones por VPH que causan cáncer, es importante que las mujeres que están vacunadas continúen haciéndose exámenes de detección habituales de cáncer cervicouterino. Así también, hay que continuar el diagnóstico temprano en las mujeres que no entran en los grupos de edad protegidos por la vacuna.

Por las razones anteriores este trabajo se plantea investigar qué barreras culturales y sociales persisten en la población femenina vulnerable para que no hagan uso del examen del Pap, así como las motivaciones que existen en mujeres que sí acceden al examen del Papanicolaou. Para exponer ampliamente la problemática social (factores sociales y culturales) que conlleva a esta enfermedad es importante mencionar el significado epidemiológico del cáncer cervicouterino, así como qué es la prueba Papanicolaou, situación que a continuación se abordará.

\section{EI Virus del Papiloma Humano: Principal mecanismo implicado con el Cáncer Cérvicouterino}

Aranda (2010) señala que, entre los factores de riesgo, el factor biológico con el $\mathrm{CaCu}$ es el virus del papiloma humano por sus siglas (VPH). "Su descubrimiento en 1976 ha ido desencadenando relaciones con el cáncer cervical rápidamente" (pág. 92). El VPH es contagiado por medio de las relaciones sexuales, es decir, se puede transmitir de una persona a otra durante el coito sexual, por lo que el hombre juega un papel importante en la transmisión del VPH y desarrollo del cáncer cervicouterino, contrario a las mujeres, los hombres no presentan síntomas o si los presentan éstos no representan un peligro para su salud, ni mucho menos para su vida.

El virus del papiloma humano es un virus de ácido desoxiborribonucleico (ADN) y representa una de las infecciones de transmisión sexual (ITS) más usuales, actualmente se conocen más de 100 tipos virales que, en relación a su patología oncológica, se clasifican en tipos de bajo y de alto riesgo de cáncer; Harold Zur Hausen y Lutz Gissman descubrieron entre el año de 1981 y 1984 los tipos de VPH asociados a tumores genitales: las tipologías 6 y 11 asociados a neoplasias benignas, como el condiloma acuminado y los tipos 16 y 18 asociados al cáncer 


\section{DOXA}

pISSN: 2395-8758

eISSN: en trámite

cervicouterino (Walboomers (1999) citado en Berumen (2006).

Con estos descubrimientos se inició el estudio intenso del VPH a nivel mundial y su asociación con esta enfermedad $(\mathrm{CaCu})$. En México, los casos de cáncer invasor se encuentran comúnmente relacionados con infecciones provocadas por estos dos tipos. Se afirma que aproximadamente el $80 \%$ de las personas tendrán contacto con este virus en el transcurso de sus vidas (Lamont, 1994).

\section{Prueba Papanicolaou}

La prueba Papanicolaou denominada así en honor de Georgios Nicholas Papanicolaou, médico griego que fue pionero en citología y detección temprana de cáncer, también es llamada como: citología cervical o exfoliativa. Se realiza para diagnosticar el cáncer cervicouterino (Laclette 2006).

En la Norma Oficial Mexicana (NOM-014-SSA2-1994) se menciona que la prueba del Papanicolaou es para la prevención, detección, diagnóstico, tratamiento, control y vigilancia epidemiológica del cáncer cervicouterino, señala también esta norma, en el portal del Centro Nacional de Equidad de Género y Salud Reproductiva(CNEGSR, 2017), que debido a que en nuestro país el perfil epidemiológico muestra incremento en la incidencia de esta enfermedad, se considera un problema de salud pública, por lo que es necesario subrayar como estrategia principal, la coordinación de los sectores público, privado y social para afrontar este padecimiento con mayor compromiso, eficiencia y eficacia Es también importante lograr una participación activa de la comunidad en la solución de este problema de salud, lo cual se logra mediante la enseñanza, difusión y concientización de los riesgos y complicaciones de la misma (NOM-014-SSA2-1994).

\section{Periodicidad de la prueba de Papanicolaou}

La Norma Oficial Mexicana NOM-014-SSA2-1994, señala que la prueba Papanicolaou se realizará cada tres años en aquellas mujeres con dos citologías previas anuales consecutivas, con resultado negativo a infección por virus del papiloma humano, displasias o cáncer; las mujeres con los problemas anteriores serán objeto de un seguimiento en una clínica de displasias $\mathrm{y}$, cuando sean dadas de alta, reiniciarán la periodicidad 
pISSN: 2395-8758

eISSN: en trámite

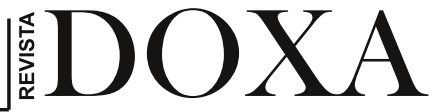

anualmente. Las mujeres con resultados positivos a procesos inflamatorios inespecíficos deberán continuar con exámenes anuales hasta que haya dos resultados consecutivos negativos. En teoría, dentro de las instituciones del Sector Público la citología deberá practicarse gratuitamente, sin exclusión de ninguna mujer solicitante por razones económicas o de edad, pudiéndose brindar el servicio a quien lo solicite con mayor periodicidad.

El Centro Nacional de Equidad y Género y Salud Reproductiva (CNEGSR, 2016), señala que la prueba debe iniciarse a partir de los 25 años en mujeres con antecedente de haber iniciado relaciones sexuales, las dos primeras detecciones son anuales y si el resultado de ambas es negativo, el Papanicolaou se realiza cada tres años. En mi experiencia algunos médicos recomiendan hacerse la prueba cada año, pero en realidad no es necesario, ya que el desarrollo del cáncer tarda entre 15 y 20 años (Lamont, 1994), por lo que hay varias oportunidades para descubrir a tiempo una lesión precancerosa. Es muy importante acudir por los resultados, en caso de un resultado anormal todas las instituciones de salud de seguridad social y de la Secretaria de Salud cuentan con clínicas de colposcopía las cuales son necesarias para hacer un diagnóstico adecuado, darle el mejor tratamiento según su caso o derivarla a un centro oncológico (CNEGSR 2016).

\section{Prueba Papanicolaou ante el Cáncer Cervicouterino}

La experiencia de países desarrollados ha permitido demostrar que la mejor opción para disminuir la mortalidad por $\mathrm{CaCu}$ es la detección y el tratamiento pertinente de lesiones precursoras y lesiones malignas por medio de Programas de detección temprana del $\mathrm{CaCu}$ que promuevan la prueba Papanicolaou citología cervicouterina. Esta es efectiva para reducir las tasas de incidencia y mortalidad, sobre todo si se realiza en el marco de un programa de prevención organizado (OPS, 2012). Además de Tinelli y Vergara (2007) la NOM-014 SSA2-1994, mencionada líneas arriba, señalan que es el método más importante en la detección del cáncer cervicouterino.

Hidalgo-Martínez (2006) señala que, desde la década de los setenta, específicamente en 1974, en México se implementó un Programa Nacional de Detección Oportuna del Cáncer por sus siglas (PNDOC) por medio de la prueba de Papanicolaou (Pap). El Programa pretende brindar información y servicios para garantizar la cobertura en la prevención y el control del cáncer 


\section{DOXA}

pISSN: 2395-8758

eISSN: en trámite

cervicouterino a fin de disminuir la mortalidad por esta causa. Incluye acciones de promoción, detección, diagnóstico y seguimiento de las mujeres de 25 años y más de edad, con una periodicidad del cribado ${ }^{5}$ de 3 años para aquellas con resultados negativos en dos citologías previas anuales (SSA, 2012).

A pesar de iniciado el PNDOC desde la década de los setenta, actualmente el cáncer cérvicouterino sigue siendo una de las principales causas de muerte para las mujeres mexicanas, como se menciona líneas arriba. Se estima que gran parte de los casos en que se desarrolla el $\mathrm{CaCu}$, se vincula a que las mujeres son de escasos recursos o que se tiene un acceso limitado a los servicios de salud, por lo que muchas mujeres no se realizan la prueba de Papanicolaou oportunamente (Lazcano et al, 1999).

Esto conlleva a valorar las razones para el no uso, que pueden ser desde que no han sido bastante informadas acerca de los beneficios para su salud, hasta la calidad del servicio de atención para realizar el examen, lo cual indica que el PNDOC a través de los años no ha ahondado suficientemente en las prácticas y actitudes de las mujeres y sus parejas en cuanto a la prueba Papanicolaou.

Una de las barreras culturales que se ha encontrado es que las mujeres tienden a vincular las causas de esta enfermedad con factores que son valorados en nuestro contexto cultural como negativos: mencionan con frecuencia que se debe a que las mujeres tienen múltiples parejas sexuales; no consideran el rol que juega el hombre en la transmisión del VPH ya que él es el portador de este virus, sin embargo ellas asignan la responsabilidad únicamente a conducta sexual de las mujeres (Hidalgo-Martínez, 2006).

Tejada y Hernández et al (2012) mencionan que otro factor importante en cuanto a la falla del PNDOC, es la falta de información adecuada respecto a la utilidad del examen del Pap, ya que señala que las diferencias socioeconómicas y algunos enfoques mal detallados de los servicios médicos han incidido para que muchas mujeres perciban los exámenes de diagnóstico o tamizaje no como una fase de prevención sino de cura. Por ello, muchas mujeres piensan que basta con hacerse la prueba Papanicolaou una vez y ya están "curadas", o que nunca van a sufrir de este

5 Cribado en medicina es una estrategia aplicada sobre una población para detectar una enfermedad en individuos sin signos o síntomas de esa enfermedad. 
cáncer. Tejeda y Hernández et al (2012) sugieren que cerca de un tercio de las mujeres ni siquiera vuelven a buscar los resultados y aquellas que lo hacen, tienen grandes dificultades para comprender las explicaciones o instrucciones de qué es lo que procede en estos casos.

Estos últimos autores comentan que cuando la prueba del Pap es positiva se les dice que necesitan otra consulta, que es necesario realizar más exámenes, porque es posible que tengan un cáncer, y que esto conlleva a la desesperación de las mujeres; especialmente este efecto se hace presente entre las mujeres de menores recursos y educación, porque les resulta difícil comprender y acudir a otras consultas, por el tiempo y el costo que esto provoca en su familia.

En conclusión, como ya se ha percibido en datos mencionados a lo largo de este documento, el cáncer cérvicouterino es una de las patologías que se ha incrementado con el trascurrir de los años en países en vías de desarrollo, en relación con su incidencia y su mortalidad (CNEGSR, 2015). El cáncer cervicouterino es prevenible y curable en un gran porcentaje si se detecta oportunamente, y en muchos países desarrollados la prueba del Papanicolaou ha sido la clave para disminuir la mortalidad; sin embargo, en México la cobertura es muy baja. En 2010 fue de 43.2 por ciento el promedio nacional y el 48 por ciento de los casos diagnosticados se encontraban ya en etapas avanzadas (Moreno 2014).

\section{El contexto mexicano}

En México y en América latina en general, es importante mencionar que los estudios de corte cualitativo sobre el cáncer cervicouterino y sobre la prueba Papanicolaou constituyen un tema muy poco explorado (Ramos y Aguilera et al, 2012), por lo que es pertinente mencionar que es de suma importancia realizar un estudio destinado a comprender las barreras culturas y sociales que sobre la Prueba Papanicolaou tienen las mujeres de 18 años y más que habitan colonias populares del norponiente y centroponiente de Ciudad Juárez, Chihuahua, además es menester señalar que los estudios sobre el cancer y el pap que abordan sus dimensiones subjetivas y sociales son escasos; y que eso es de notarse porque esta enfermedad esta relacionada con la sexualidad, la cual es un eje importante de la vida de los individuos. en las mujeres, la sexualidad es un aspecto alrededor del cual giran numerosos 


\section{DOXA}

pISSN: 2395-8758

eISSN: en trámite

significados y practicas.

Esta investigación resulta importante dado que el cáncer cervicouterino es la segunda causa de muerte tanto a nivel nacional como en el estado de Chihuahua (Rivas, 2012); en Ciudad Juárez los casos por $\mathrm{CaCu}$ van en aumento en mujeres de 24 años en adelante (Gamboa, 2015). Ochoa (2016) menciona que las muertes por cáncer cérvicouterino en el estado de Chihuahua aumentaron $24.7 \%$ en 5 años. En México la tasa promedio de mortalidad de este padecimiento es de 14.2 por cada 100 mil mujeres de 25 años y más (Moreno, 2014). Entonces se puede decir que el estudio de esta enfermedad desde un enfoque social, permitiría describir y comprender en un sentido más amplio las barreras culturales y sociales que intervienen para la no realización de la prueba Papanicolaou.

Un estudio de esta naturaleza permitiría comprender y describir un panorama ampliado, de las representaciones sociales que sobre la Prueba Papanicolaou, el cáncer cervicouterino y el virus del papiloma humano, tienen las mujeres de esta región. Esta investigación tiene la intención de generar insumos para la reformulación de políticas públicas, en prevención y cuidado que posiblemente incidirían en la disminución de la prevalencia de las muertes por $\mathrm{CaCu}$. En cuanto al interés de investigar esta temática en mujeres que habitan colonias populares, radica en que en Ciudad Juárez dichas colonias tienen un foco rojo en cuestión problemáticas de género, como violencia, salud, etc. (Cervera y Monarrez, 2011, Pág. 56).

El cáncer cervicouterino $(\mathrm{CaCu})$ representa uno de los problemas de salud pública más estudiados desde los más diversos frentes: a nivel administrativo y de política pública, se han analizado los pros y contras de los planes y programas dirigidos a su prevención y detección oportuna, sus coberturas y su costo-efectividad a nivel epidemiológico (Lazcano, 2006). Como se ha mencionado líneas arriba, se han estudiado las características de los principales serotipos del Virus de Papiloma Humano (VPH) asociados al desarrollo de $\mathrm{CaCu}$, así como a nivel histopatológico el crecimiento y comportamiento de tejidos neoplásicos (epidemiológicas), así como también existen numerosos estudios cuantitativos. Sin embargo, aún son escasas las investigaciones centradas en el sentir y en la voz de la mujer respecto de las acciones preventivas como la prueba Papanicolaou y/o de la experiencia de enfermar de cáncer cervicouterino. 


\section{Representaciones sociales}

Una de las teorías que puede apoyar para conocer las causas por las que las mujeres no se realicen a tiempo la prueba Papanicolaou es la de "las representaciones sociales". Diversos estudios la han utilizado; ChávezMendez et al, (2012), Aranda (2005) Rocha (1995), Rico (2010) entre otros.

Ellos a su vez señalan la importancia de indagar las representaciones sociales en referencia al cuidado de la salud y sobre las diferentes prácticas asociadas a ellas con el fin de analizar el "anclaje" social de su construcción, así como la objetivización: lo social en la representación, las representaciones sociales y su interiorización en el individuo, sujeto social y teoría genética.

Se considera que el papel que tiene la cultura en el comportamiento humano es un factor relevante en la adopción de una modalidad del cuidado de la salud por parte de los sujetos sociales así como los aspectos culturales que pueden afectar el que la mujer no se realice la prueba Papanicolaou (Candreva y Paladino), en este apartado figuran los tópicos de género y salud, creencias culturales y prueba Papanicolaou, estructura social y sexualidad, interpretaciones socioculturales y sexualidad, significaciones culturales de género, las relaciones de poder y cáncer cervicouterino y por último género y el ejercicio de la sexualidad.

Asimismo se analizan los estudios que se han realizado tanto en América Latina como en México y que han ayudado a formar parte de una mejora a las políticas públicas existentes en este país referente a los entramados culturales que afectan a que la mujer se preocupe por su salud o más específicamente a que ella se realice o tenga acceso a la prueba Papanicolaou.

Rocha en Aranda (2010) define las representaciones sociales de la enfermedad como

"la forma de conocimiento de sentido común que construyen los individuos con relación a las enfermedades, tanto en su sentido genérico como específico. Es decir, se entienden como sistemas de ideas, creencias e imágenes en cuanto a las enfermedades, su origen, clasificación, la caracterización de una situación de enfermedad y las implicaciones de la misma" (Pág. 59).

Estos sistemas son dinámicos y cambian en la medida en que el 
sujeto interactúa con su medio social. Aún cuando son dinámicos, por lo general, permanecen ciertos núcleos compartidos entre individuos, otros elementos cambian y presentan matices diversos. Es importante señalar que los tiempos de permanencia de los elementos que conforman las representaciones son diversos, mientras que algunos elementos son más estables, otros cambian de una generación a otra.

Como mencionan Chávez Méndez et al, (2012) que aunque el concepto de representación social ${ }^{6}$ se encuentra en diversa literatura tanto de psicología como de psicología social, su desarrollo conceptual y formulación teórica es relativamente reciente y se debe a Sergio Moscovici en 1961. La finalidad de este psicólogo social es la de reformular en términos psicosociales el concepto durkheimiano de representación colectiva. Para Durkheim las representaciones colectivas son formas de conocimiento o ideación construidas socialmente, que no pueden explicarse como consecuencias de la vida individual o recurriendo a una psicología individual. (Moscovicci citado en Rojas, 2012).

Sanabria (2012) señala que el conocimiento es uno de los parámetros más importantes y determinantes para que una mujer se realice la prueba del Papanicolaou, se trata de saber lo que ellas piensan y saben al respecto, y muchas veces la información que ellas manejan es la que determina si se lo hacen o no (Pág. 85).

Según Moscovici (1981) el concepto de representación social difiere del de representación colectiva en que el primero tiene un carácter más dinámico. En opinión de este psicólogo social, las representaciones sociales no son sólo productos mentales, sino que son construcciones simbólicas que se crean y recrean en el curso de las interacciones sociales.

Las representaciones sociales, como lo señala Jodelet (1988), están relacionadas con las imágenes que condensan un conjunto de significados, es decir con la articulación de sistemas de referencia que nos permiten interpretar lo que nos sucede y generar categorías que sirven para clasificar las circunstancias, los fenómenos y a los individuos. En este sentido, se

6 La noción de las representaciones sociales nos sitúa en el punto donde se unen lo psicológico y lo social. Por tanto, hablar de representaciones sociales, es referirse a la forma en la que, como actores sociales, aprehendemos los acontecimientos de la vida diaria, las características de nuestro contexto social y ambiental, las informaciones que en él circulan, a las personas de nuestro entorno próximo o lejano. En pocas palabras es hablar del conocimiento del sentido común o pensamiento natural; que en otros términos se trata de un conocimiento práctico (Moscovicci, en Chávez Méndez, (2012). 
considera que a través de estas representaciones se puede establecer y explicar la interrelación de los factores psicosociales (creencias, actitudes, género, ocupación, condición social, etcétera) que intervienen en el proceso de significación sobre salud-enfermedad de cada individuo.

Moscovici (1981) señala que la utilidad de las representaciones sociales radica principalmente en que sirven para interpretar y construir sentido de nuestra realidad cotidiana y, con ello, se pueda construir un conocimiento social (Moscovicci citado en Rojas, 2012).

\section{Capital Social}

Dentro de los estudios que involucran el concepto de capital social, su definición no ha resultado, hasta la fecha, completamente satisfactoria para la comunidad científica. Dicho de otra forma, no existe una definición clara sobre lo que se implica cuando se habla de capital social, sin embargo, hay algunos acercamientos que pueden resultar útiles para situar la definición de capital social desde una óptica social. Pierre Bourdieu en 1980 publica un artículo de investigación donde define el capital social como "recursos potenciales o actuales asociados a la posesión de una red duradera de relaciones más o menos institucionalizadas de conocimiento y reconocimiento mutuo. Expresado de otra forma, se trata aquí de la totalidad de recursos basados en la pertenencia a un grupo. El capital total que poseen los miembros individuales del grupo les sirve a todos. En la práctica, las relaciones de capital social sólo pueden existir sobre la base de relaciones de intercambio de materiales y/o simbólicas, y contribuyen además a su mantenimiento" (Bourdieu, 1986).

Putnam entiende esencialmente el capital social como un conjunto de redes sociales, que crean un cierto nivel de vida asociativa en una comunidad determinada y en cuyo seno se generan normas de reciprocidad en las que la confianza interpersonal es producto clave que hace posible la cooperación y permite la eficiencia social al facilitar las acciones coordinadas (1993:167-176). En corto, puede colegirse que el capital social está definido en función de la densidad asociativa de una sociedad específica.

A través de Making Democray Work, Putnam observa que la densidad asociativa permite, en principio al interior de las redes sociales (desde clubes de fútbol hasta grupos corales o clubes de lectura), que los 


\section{DOXA}

pISSN: 2395-8758

eISSN: en trámite

ciudadanos que participan en asociaciones voluntarias y esencialmente horizontales, más tarde planteen de forma agregada demandas que beneficien a la sociedad en su conjunto. Así, revela el estudio hecho para Italia, cuanto mayor sea la densidad de vida asociativa mayor será la capacidad de los ciudadanos de una región determinada para cooperar y actuar para obtener beneficios mutuos $\mathrm{y}$, en consecuencia, plantear demandas de bienes públicos y mejor respuesta tendrán por parte de los políticos regionales. La tesis de Putnam, desde luego, ha sido recibida con interés y escepticismo. Varias reflexiones apuntan a algunos problemas en la definición de capital social del autor, así como, gracias la ambigüedad a la hora de definir las instituciones, de la relación causal entre capital social y desarrollo institucional-social. Más allá de eso, el libro demuestra la importancia que tiene el capital social para resolver los problemas de comportamiento egoísta, dilemas típicos de la acción colectiva.

La forma como identifica el capital social Coleman, a partir de la estructura social, en el entendido que ésta "pone a los actores como recursos y que ellos los pueden usar para lograr sus propios intereses" ... Todas las relaciones sociales y estructuras sociales facilitan algunas formas de capital social; los actores establecen relaciones a propósito y las continúan para seguir proporcionando beneficios. Sin embargo, ciertos tipos de estructura social son especialmente importantes para facilitar algunas formas de capital social" (Coleman, 1988, p. 101-102).

De acuerdo con la CEPAL el "capital social permite poner de relieve los efectos positivos que pueden esperarse de la creación y uso del capital social, tales como control social, creación de confianza entre individuos, cooperación coordinada, resolución de conflictos, movilización y gestión de recursos comunitarios, legitimación de líderes y generación de ámbitos de trabajo, la prevención y sanción de quienes abusan de él y la producción de bienes públicos" (CEPAL, 2001).

Regularmente se suele pensar en las ventajas que da el capital social al desarrollo comunitario, o incluso al desarrollo económico. Teóricamente, estamos acostumbramos a pensar en el CS como una herramienta que genera confianza y cohesión social en las comunidades, sin embargo, es necesario saber las formas o prácticas sociales que se pueden dar dentro de las comunidades y que pueden ser diferentes a la que se espera con el capital 
pISSN: 2395-8758

eISSN: en trámite

social.

Como en los anteriores autores, en varios estudiosos del capital social, se cree que el capital social puede ser pionero en la generación del desarrollo social y económico, sin embargo, hay perspectivas que cuestionan esta idea, o al menos, hacen algunas preguntas hacia este precepto. Barbara Arneil se hace la pregunta ¿es tan poderoso el capital social?, y comenta que no necesariamente, hay diversas comunidades: el problema del capital social. De hecho, hay una buena razón para pensar que una fijación con capital social es equivocada, incluso peligrosa para grupos menos poderosos de la sociedad, como mujeres, minorías etnorales, gays y lesbianas y personas con discapacidades (Arneil 2006) debido a los intereses individualistas o egoísmo. Arneil sostiene que la división, la diversidad y los conflictos deben ser considerados como un desafío en el contexto norteamericano, habla de la dominación de los hombres blancos, nacidos en el país y de clase media, y lo que hace poco fácil de implementar la idea de capital social.

En su caso, Arriagada, el capital social puede ser perverso "en el cual las redes, contactos y asociaciones están al servicio de las actividades ilegales" (Arriagada, 2003, 572); por esto retoma a Rubio, quien muestra un contexto donde el capital social no produce efectos positivos, "la existencia en Colombia de una economía ilegal importante y creciente, fomentada por organizaciones criminales de mucho poder, que ha dado origen a una institucionalidad paralela que retribuye y favorece comportamientos criminales. El autor muestra cómo altos niveles de capital social dentro de las organizaciones criminales son reorientados hacia actividades extra-legales que reditúan altos beneficios para aquellos involucrados en estas actividades" (Rubio citado por Arriagada, 2003, 572).

El capital social bien orientado puede potenciar la cohesión comunicatoria, debido a que las personas confían más entre ellas, genera mayor comunicación, se pueden identifican de manera colectiva los problemas, las personas se ayudan mutuamente, es decir, hay varias razones por las cuales el capital social puede ser un activo importante para el desarrollo comunitario, sin embargo, implementarlo no es tan sencillo, o incluso esperar que se den los resultados como teóricamente se espera, no es fácil. Porque dentro de las comunidades hay prácticas ancladas en el autoritarismo, clientelismo, paternalismo, egoísmo, entre otras, por lo que, al 
querer implementar capital social como estrategia de intervención social, estas formas pueden surgir dentro de las comunidades y los objetivos que se habían marcado como positivos, en realidad, pueden ser negativos.

Haciendo referencia a Arriagada, dice que el clientelismo es una de las formas de capital social que puede ser negativo, debido a que no se promueve el desarrollo de las comunidades, al contrario, se convierten en receptores de la política social, "el clientelismo es uno de los problemas centrales y más antiguos en la relación entre organizaciones comunales y de base, y los agentes estatales y no gubernamentales en América Latina. Pueden distinguirse distintos tipos de clientelismo en un continuo que va desde el autoritario al paternalista. A tales tipos de relación pueden agregarse otros que son más proclives a potenciar el capital social colectivo, como la capacitación de los miembros de las organizaciones hasta que éstas alcancen su autonomía, y a quienes los funcionarios públicos y privados deben rendir cuentas" (Arriagada, 2003, 572-573).

Uno de los ejemplos que se puede tener de un capital social negativo es cuando una comunidad se organiza para linchar a un violador o a un asesino, o en su caso por, los grupos que se organizan para fines del narcotráfico. Estos grupos se crean de manera colateral con fines distintos a favorecer el Estado de Derecho, es decir, un lugar donde se cumplen las leyes. De acuerdo con Rivera, este tipo de capital se produce en grupos sociales muy particulares, "un ejemplo de Capital Social negativo son las organizaciones mafiosas (pandillas, delincuencia organizada, narcotraficantes, entre otras), construidas y mantenidas con base en fuertes lazos informales como la confianza, la reciprocidad y la lealtad, que, aunque pueden rendir altos beneficios a sus miembros, asimismo pueden ser negativos y altamente dañinos para el entramado social en el que se desarrollan" (Rivera, 2016, 118). En su caso cuando hay comunidades muy cerradas o que socializan pocos con el vecino, cuando la comunidad conoce a una persona que comete un delito y no lo denuncia. $\mathrm{O}$ sabe dónde venden drogas y no se denuncia. Es en este sentido que es un capital negativo.

\section{Análisis de resultados}

En este presente apartado se hace un análisis descriptivo de las entrevistas realizadas a catorce mujeres de la zona norponiente y centro poniente de 
pISSN: 2395-8758

eISSN: en trámite

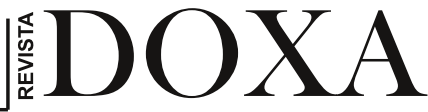

Ciudad Juárez, Chihuahua, el propósito general es identificar las barreras culturales y sociales que las mujeres tienen para no realizarse la Prueba Papanicolaou a tiempo, a través de la narrativa de las mujeres entrevistadas.

En el análisis se hace uso de las categorías "central" y "periférica de Jean Claude Abric (1994), donde se destaca que los tiempos de espera para la atención y respuesta de resultados, la cantidad de personas que atienden, el mal trato y la ausencia de especialistas en dichas entidades, constituyen otro factor determinante en la práctica del examen ya que las instituciones públicas son muy lentas y les hacen perder mucho tiempo, pero el problema radica cuando no todos los sectores de la población pueden tener acceso a los servicios que presta el servicio privado, también como la construcción social de género, dificulta la práctica de realizarse la prueba Papanicolaou como método de prevención para un posible desarrollo del $\mathrm{CaCu}$, lo que constituye otra barrera o limitante que impiden que la mujer no acuda a los métodos de prevención sobre su propia salud.

\section{Representación social del cáncer cervicouterino}

En esta fase las mujeres enunciaron la información que poseen acerca del cáncer cervicouterino y en su narrativa se identifica que muy pocas de las entrevistadas se refirieron al orden científico sino más bien se guiaron por el sentido común. Sus nociones socio cognitivas están estrechamente vinculadas al conocimiento que se da por medio de juicios interpretativos entre familiares y amigas, lo que se relaciona con un capital social limitado en términos de apoyo social y carente de información clara y veraz, muy poca información proveniente del sector salud y la comunidad no transfiere la información de manera oportuna y clara, hay momentos que se construye se distorsiona la información, es decir, cada quien entiende lo que quiere.

Las entrevistadas expresaron, de manera espontánea, un número importante y variado de información acerca del cáncer cervicouterino, como lo mencioné líneas arriba, no fueron tantas nociones del orden científico, sino que fueron elementos del sentido común. Sus nociones sociocognitivas que aparecen argumentadas en las fases posteriores mediante juicios interpretativos manifiestan cierto nivel de contradicción, de esta forma, se perfilaron los niveles centrales y periféricos de la representación social del $\mathrm{CaCu}$ y, que se presentan en la siguiente figura sobre: el núcleo central y sistema periférico sobre el conocimiento del cáncer cervicouterino. 


\section{DOXA}

pISSN: 2395-8758

eISSN: en trámite

La información que proporciona el sector salud, es limitada o por lo tanto a veces incomprensible para algunas mujeres, en algunos casos como se manifiesta en los siguientes subtemas en este mismo apartado de resultados, la información que provee el sistema de salud al público en general, es carente e insuficiente, ya que el personal médico no explica detenidamente algunos aspectos que rodean la información de la enfermedad como: factores de riesgo, la utilidad de la prevención, consecuencias de la enfermedad, etc. Ellas mismas manifiestan su poco o total desconocimiento sobre este padecimiento, mencionan que sólo obedecen indicaciones del médico como el de ir a realizarse la prueba pero no se adentran en aspectos básicos de la enfermedad como utilidad de la prueba, qué es el $\mathrm{CaCu}$, etc. “...el doctor solo me dijo que me la hiciera porque estaba embarazada... pero a veces no te dice para qué, solo que para que no se me haga cáncer y pues no afecte a la criatura, pero nada más" (E7, 7 de julio, 2016).

Las mujeres que padecen esta enfermedad e inmediatamente las entrevistadas revelan ellas mismas un desconocimiento efectivo sobre el cáncer cervicouterino, dentro de la propias familias, encontramos información distorsionada, en cierto sentido es un capital negativo, su base principal esta basa de mitos o en el sentido común, esto implica que no hablan sobre bases científicas de la enfermedad, es decir están alejadas del discurso científico. "pues mire no sé mucho, pero me han dicho o he sabido que esa enfermedad tiene que ver con la muerte... la hermana de mi comadre tuvo..." (E2, 4 de julio, 2016). Mencionan (5 de 14) que es peligrosa por el simple hecho de ser un cáncer; mientras algunas (4 de 14) señalan que es una enfermedad curable, la mayoría señala que es incurable y peligrosa ( 8 de 14).

Aunque ignoren a detalle el padecimiento, todas mencionan que es por medio de la prueba Papanicolaou. Las entrevistadas se descalifican y mencionan que no tienen conocimiento; encontramos que las mujeres únicamente comparten sus experiencias con sus familiares o con amigas, sin embargo, son círculos muy cercanos, hay una secrecía dentro de la propia comunidad, en lugar de compartir sus experiencias, la información se queda en círculos muy cercanos.

Respecto a las fuentes de información, las entrevistadas señalan que lo que conocen del PAP es por familiares y amigas que les mencionan que se deben realizar la prueba Papanicolaou, sin embargo, al información está 
pISSN: 2395-8758

eISSN: en trámite

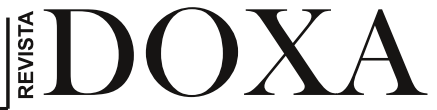

basada en el sentido común y en rumores.

La representación social de la prueba Papanicolaou, señalan las entrevistadas les surgen emociones como: miedo, nervios, vergüenza, dolor, factores importantes presentes cuando se realizan la prueba Papanicolaou que su vez han sido elementos determinantes para que no se siguieran realizando la prueba, estos señalamientos se dan más en las entrevistadas que acuden a realizarse el examen a servicios médicos públicos como IMSS, ISSSTE o Seguro Popular.

Además, mencionan sus experiencias negativas: el maltrato del personal médico al realizarse el examen, otras señalan que les han "contado" que los resultados salen dudosos en servicios de salud públicos como en algunos programas sociales del gobierno. Otras mencionan que la realización de la prueba en servicios de salud privados es mucho mejor que en uno público y también sugieren que actualmente se conoce más sobre este examen no por medio de propaganda gubernamental o medios de comunicación sino, por la información que se han obtenido mediante amigas, hermanas, primas, vecinas, etc. En conclusión, la narrativa obedece a una estructura representacional que puede incluir ciertos componentes ambiguos y contradictorios sobre la prueba Papanicolaou y que la propia comunidad no hay redes de apoyo que fortalezca la información clara y veraz de la prueba.

\section{Conclusiones}

En primera instancia se identificó que el nivel de conocimiento que las mujeres tienen sobre la citología cervicouterina y prueba Papanicolaou, es mínimo en lo que respecta al significado y como consecuencia a su impacto real, de tal manera que, si el concepto en su percepción es "pobre", su ejercer se traduce en una práctica también mínima.

De igual manera, otra de las barreras vinculadas a la perspectiva de género, es que los programas sobre el $\mathrm{CaCu}$, no tienen en cuenta la diversidad étnica, económica, cultural y de región de residencia de las mujeres en el diseño de los programas informativos, lo que complica que estos datos no lleguen de manera adecuada a las usuarias. En otras palabras, esta diversidad de situaciones condiciona la llegada de la información y el acceso real de las mujeres a los servicios de salud y por lo tanto a la posibilidad de realizarse el examen de detección oportuna. 


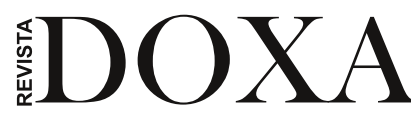

pISSN: 2395-8758

eISSN: en trámite

Asimismo, se enfatiza que los médicos tampoco contribuyen, en especial, aquellos que trabajan en los servicios de salud públicos, ya que su lenguaje técnico dificulta que las mujeres "entiendan" el significado, así como los beneficios de la prueba Papanicolaou, así como del cáncer cervicouterino.

El conocimiento que las mujeres tienen de "su" realidad con respecto al asunto de la presente materia de investigación, refuerza lo que Luckman (1967) sostiene al descubrir la relación entre la representación y el objeto que la origina, así como su surgimiento y evolución a través de la comunicación pues uno de los cimientos de la teoría de este autor señala que "La naturaleza de esta generación y construcción, del concepto, es social pues pasa por la comunicación y la interacción entre los sujetos, grupos e instituciones", ya que este trabajo de estudio demostró que uno de los factores determinantes en el déficit de conocimiento sobre el tema es el "nivel" de información y prácticas deficientes de las entidades encargadas de la salud.

El nivel escaso de información se fundamenta en la "interacción" que refiere Luckman (1967) en el sentido de que en este caso el responsable de ofertar los servicios preventivos para una detección temprana, el Sistema Nacional de Salud, se limita a emitir "comunicados" en un solo sentido sin "comprobar" la efectividad de su concientización y por lo tanto de resultados en lo que refiere a los retos que las mismas entidades promulgan a través de sus "Programa de Acción: Cáncer Cérvico Uterino", detallados en el apartado de "Género, equidad de género y políticas públicas" de esta investigación, con respecto a la atención y esfuerzos coordinados por las instituciones de salud entre los que están además de la difusión, la vigilancia de la aplicación de la normatividad y lineamientos de los programas, práctica que no se ejerce, pues como punta (Bautista, 2007:676), este tipo de fenómenos tiene que ver con el hecho de como las personas representan al cáncer cervicouterino lo que se le llama "los saberes ingenuos sobre la detección y el tratamiento", reforzado por la afirmación de Urrutia, Araya, \& Poupin, (2010, p. 287), en el sentido de que “... un aspecto necesario a considerar para incentivar a las mujeres a la realización de este examen es un cuidado en salud sensible, que otorgue una consejería sobre la importancia de realizar el Pap".

Asimismo, esta investigación arroja un fenómeno que resulta 
pISSN: 2395-8758

eISSN: en trámite

determinante en las mujeres en la realización del examen del Papanicolaou y que aunado a la narrativa limitada hacia estas por parte del aparato medico a través de los programas gubernamentales, constituye un obstáculo más: la "violencia institucional", el cual se refleja en diferentes variables que limitan el ejercicio de la práctica.

En primera instancia se encuentra la calidad del servicio por parte del personal médico cuya retórica sigue los lineamientos exiguos de los planes citados arriba ya que como señala (Bautista, 2007: 677), ... "Algunas reciben la atención indicada por los médicos, pero no se les proporciona información suficiente para identificar mejor su problema de salud, por lo que al ser atendidas no se sienten necesariamente satisfechas, pues su vivencia corporal y emocional de su padecimiento es diferente a lo diagnosticado clínicamente."

Continuando con las variables de la violencia institucional, se comprueba que un detonante concluyente en lo que respecta a la motivación para la práctica del examen del Papanicolaou es la calidad del servicio, en específico la atención médica prestada en las instituciones públicas ya que se enfoca en la cantidad y no en la calidad y cuidado de las pacientes.

Aunado a lo anterior, queda de manifiesto que los tiempos de espera para la atención y respuesta de resultados, la cantidad de personas que atienden, el mal trato y la ausencia de especialistas en dichas entidades, constituyen otro factor determinante en la práctica del examen ya que las entidades públicas son muy lentas y les hacen perder mucho tiempo, cuando la prueba puede hacerse alrededor de unos cinco minutos, cuando alguien se hace la prueba en un hospital privado, las diferencias son muy marcadas, pero el problema radica cuando no todos los sectores de la población pueden tener acceso a los servicios que presta el servicio privado, los precios exceden sus posibilidades económicas, incluso no solo los costos de la prueba sino los propios tratamientos.

La narrativa de las conversaciones proyectó que las mujeres entrevistadas, en efecto sí anteponen el rol de la maternidad, ya que el cuidado de los menores y otras personas (como su pareja o adultos mayores), así como su "seguridad" es algo sumamente prioritario para ellas, lo que hace que posterguen el cuidado de su propia salud. Es decir, observamos cómo la construcción de las subjetividades femeninas y masculinas determina las 


\section{DOXA}

pISSN: 2395-8758

eISSN: en trámite

formas de existir de cada uno de ellos, de enfermar, de padecer, de buscar placer, así como de ejercer su sexualidad.

Otra condicionante sociocultural es el manejo de la sexualidad equitativamente, es decir, con responsabilidad para ambos y que no está contemplada en ningún programa de gobierno, ya que únicamente mencionan una orientación a las mujeres y hombres en cuanto a su compromiso en el autocuidado de la salud y sobre su participación en los factores de riesgo de la enfermedad, siendo uno de estos factores las múltiples parejas sexuales (del hombre y de la mujer). Lo que no contempla es el cómo abordar el factor sociocultural, ya que como lo mencionan Moreno (2014) e Hidalgo-Martínez (2006), donde señalan que no se ha puesto la atención que se requiere al hecho de que el hombre es portador del virus del papiloma humano (VPH) y, donde predominantemente dentro de la sociedad se establece a la mujer como única responsable de esta enfermedad.

\section{Referencias}

Abric, J.C (1994) Prácticas Sociales y Representaciones. Filosofía y Cultura Contemporánea. Ediciones Coyoacán S.A de C.V. México.

Aranda, Gallegos P, Saberes relacionados con el Papanicolaou y el cáncer cervicouterino: estudio con derechohabientes del IMSS, en Hermosillo, Sonora, 2005.

Arneil, B. 2006. Diverse Communities: The Problem with Social Capital. (Cambridge). Cambridge: Cambridge University Press.

Arriagada, Irma. 2003. Capital social: potencialidades y limitaciones analíticas de un concepto Estudios Sociológicos, (septiembrediciembre), 557-584.

Bourdieu, P. 1986. The forms of capital. In J. Richardson (Ed.) Handbook of Theory and Research for the Sociology of Education (New York, Greenwood), 241-258.

Caraveo Valdez R; Factores que influyen en el comportamiento preventivo del Cáncer Cervicouterino; realizado en Chihuahua, México en 2004.

Castorina, J.A. Representaciones Sociales. Problemas Teóricos y Conocimientos Infantiles. Barcelona, España, 2003.

Castro Reyes, E, Machado M, Andres P, Borre Arrieta O, Conocimientos, 
actitudes y prácticas acerca del virus del papiloma humano en adolescentes escolarizados, Revista Ciencias Biomédicas, 2012.

Cejudo, Guillermo M., y Cynthia L. Michel. 2015. "Resolviendo problemas sociales complejos mediante la integración de políticas. El caso de la Cruzada Nacional contra el Hambre en México". Reforma y Democracia (63): 35-45.

Centro Nacional de Equidad de género y Salud Reproductiva (CNEGSR) $(\mathrm{S} / \mathrm{f})$.

http://cnegsr.salud.gob.mx/contenidos/Programas_de_Accion/C ancerdelaMujer/introduccionCancerMujer.html.

CEPAL. 2001. Capital social y pobreza, Documento preparado para la Conferencia Regional sobre Capital Social y Pobreza, Santiago de Chile.

Chávez Méndez, Ma. Guadalupe, Arellano A, Tamayo Acevedo C, Stella Levy L, Álvarez, J.R; Representación Social sobre el Cáncer Cervicouterino por mujeres jóvenes de 18 a 29 años de edad de Colima, México. A través de la aplicación de las redes semánticas naturales como estrategia metodológica, México, 2012

Coleman, J. S. (1988). Social Capital in the Creation of Human Capital.

American Journal of Sociology, 94, 95-Arneil, Barbara. 2006.

Diverse Communities: The Problem with Social Capital. Cambridge. Cambridge: Cambridge University Press.

Coleman, James S. 1988. "Social Capital in the Creation of Human Capital". American Journal of Sociology 94: 95-120.

Diccionario de Acción Humanitario y Cooperación al Desarrollo. (S/f). Disponible en http://www.dicc.hegoa.ehu.es/listar/mostrar/66. Revisado el 10 de febrero de 2016

Dirección general de servicios médicos, capsulas de salud sexual y reproductiva. (S/f). Universidad Autónoma Nacional de México. Disponible en: http://caduceo.dgsm.unam.mx/capsulas/reproductiva.html, Revisado el 3 de octubre de 2014.

Heise L, Moore K, (1995). Toubia N. Sexual coercion and reproductive health. The Population Council and Health Development Policy Projectt, New York. 


\section{DOXA}

pISSN: 2395-8758

eISSN: en trámite

Hidalgo-Martínez, A (2006); AC. El cáncer cérvico-uterino, su impacto en México y por qué no funciona el programa nacional de detección oportuna. Rev Biomed 17:81-84.

INH

"Instituto Nacional del cáncer"

(2018)

https://www.cancer.gov/espanol/cancer/causas-

prevencion/riesgo/germenes-infecciosos/hoja-informativavacuna-vph.

Jodelet, D (1988). La representación social: fenómenos, concepto y teoría. Psicología social II. Paidós, Barcelona.

Lamont, J. Psychology reactions of women to the diagnosis of conditions associated with pre-invasive cervical cancer. Canadian Journal of Human Sexuality. 1994.

Lazcano, H, Donadio, F; Rodríguez A; Alonso I; Fajardo L. (2013), Conocimientos, Actitudes y Prácticas de las Trabajadoras del sexo acerca del Virus del Papiloma Humano, Centro de Salud de Santa Ana. Distrito de Panamá.

Lazcano-Ponce E, Yunes-Díaz .EM. Evolución de las pruebas de tamizaje para la detección oportuna de cáncer. Gamo 2006; (5)4: 91-92.

Manual del Programa de Acción: Cáncer Cérvico Uterino. (S/f). http://www.salud.gob.mx/unidades/cdi/documentos/DOCSAL7 1 04.pdf. Revisado el 4 de noviembre de 2015.

Moreno Tetlacuilo, L.M. Boletín UNAM-DGCS-741 Ciudad Universitaria. 22 de diciembre de 2014. Disponible en http://www.dgcs.unam.mx/boletin/bdboletin/2014_741.html, revisado el 15 de julio de 2015.

Moscovici S (1996), Psicología de las minorías activas. Traducido por M. Olasagasti, Segunda edición, Ediciones Morata, S.L Madrid.

Norma Oficial Mexicana NOM-017-SSA2-1994 para la Prevención, Detección, Diagnóstico, Tratamiento, Control y Vigilancia Epidemiológica del Cáncer Cérvico Uterino. Publicada el 31 de mayo de 2007, en el Diario Oficial de la Federación

Ochoa M C, (2011) "Políticas públicas con perspectiva de género, UNAM.

Ramos, S.; Aguilera A.; Capriatti, A.; Lehner, P.; Pena, L. y Tamburrino, M. C. (2013). Estudio cualitativo sobre significaciones socioculturales, conocimientos y prácticas relativas al cáncer de mama, cuello de 
pISSN: 2395-8758

eISSN: en trámite

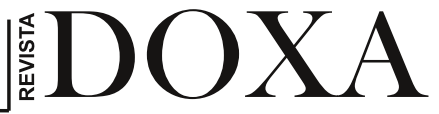

útero y colon. Informe sobre revisión de la literatura (mimeo), Buenos Aires.

Rico Blanco, Troncoso E, López M, Nigenda G, Langer A. (2010). Políticas Publicas en salud, género y mujer, Caleidoscopio de la Salud.

Rocha Rivero, G I (1995), Las representaciones sociales de la enfermedad: Una mirada sociológica a la perspectiva lega, [tesis doctoral], México DF, El Colegio de México.

Secretaría de Salud. Programa de acción específico 2007-2012 Cáncer cervicouterino. (S/f). en: http://www.spps.gob.mx/programas-y-proyectos.html/ Revisado el 20 de mayo de 2016.

Secretaría de Salud. Programa de acción específico 2013-2018 Cáncer cervicouterino. (S/f). en: http://www.spps.gob.mx/programas-accion20 13-2018.html.

Revisado el 21 de mayo de 2016.

Tejada L M, Hernández-Ibarra L E y Pastor-Durango, M P (2012), Fortalezas y debilidades del programa para la detección y el control del cáncer cervicouterino. Evaluación cualitativa en San Luis Potosí, México-

Walboomers,J. et. al. (1999) "Human papillomavirus is a nessesary cause of invasive cervical cancer Worldwide”. J. Pathol. 1999; 189:12-19. Citado por Berumen Campos, J. "Virus del papiloma humano y cáncer del cuello uterino”. Gac. Med. Mex. (2006). 